\title{
Фізико-математична модель взаємодії диска 3 ґрунтом
}

\author{
О.В. Козаченко ${ }^{1}$, К.В.Сєдих ${ }^{2}$, О.М. Волковський ${ }^{1}$ \\ ${ }^{1}$ Харківський національний технічний університет сільського господарства імені \\ Петра Василенка (м. Харків, Україна), email: o.v.kozachenko21@gmail.com \\ ${ }^{2}$ Харківський національний аграрний університет імені В.В.Докучаєва \\ (м. Харків, Україна), email: siedykh.kostiantyn@gmail.com.
}

\begin{abstract}
Представлено результати теоретичних досліджень взаємодії ґрунтового середовища з дисковим робочим органом ґрунтообробного знаряддя і визначено складові сили опору шляхом дослідження руху частинки ґрунту по увігнутій сферичній поверхні робочого органу дискатора та визначення лінії контакту ґрунтового середовища із нею; визначення площі контакту ґрунтового середовища із поверхнею робочого органу дискатора; враховуючи напруження, що виникають в ґрунтовому середовищі при дії на нього дискового робочого органу визначено складові відповідної сили опору.

В результаті аналітичних досліджень переміщення частинки ґрунту по увігнутій сферичній поверхні робочого органу дискатора з урахуванням сили підпору шару ґрунту, що напливає на дисковий робочий орган, відцентрової сили та сили Коріоліса, що виникають в результаті його обертання, розроблено програмний код в програмному пакеті Mathematica, який дозволяє визначати площу та рівняння лінії контакту ґрунтового середовища із поверхнею робочого органу дискатора в залежності від його конструктивних параметрів: радіуса сфреричної поверхні R та діаметра диска $\mathrm{d}$, кута атаки а і кута нахилу ү та глибини обробітку ґрунту $\mathrm{h}$.

Враховуючи отримані залежності площі та рівняння лінії контакту ґрунтового середовища із поверхнею робочого органу дискатора та використовуючи відомі аналітичні закономірності для компонентів нормальних напружень пружно-в'язко-пластичного ґрунтового середовища, розроблено програмний код в програмному пакеті Mathematica, який дозволяє визначати залежності проекцій сили опору від кутів атаки а і нахилу ү робочого органу дискатора, швидкості його переміщення $\mathrm{V}$ та глибини обробітку ґрунту h. Зроблені відповідні висновки щодо отриманих результатів теоретичних досліджень.
\end{abstract}

Ключові слова: дискатор, дискові робочі органи, кут атаки, кут нахилу, якість обробітку грунту, параметри сфреричного диска, енергоємність.

Постановка проблеми. Сучасні технології виробництва сільськогосподарських культур передбачають застосування дискових робочих органів машин і знарядь, що забезпечують задану якість та мінімальні енерговитрати на виконання технологічного процесу обробітку ґрунту. При цьому на означені показники суттєвий вплив мають, з одного боку, конструктивно-режимні параметри робочого органу машини, а з іншого - фрізико-механічні властивості оброблюваного середовища [1,2,3, 4]. Особливістю сучасних ґрунтообробних знарядь з дисковими робочими органами, зокрема дискаторів, є механізм впливу на оброблюване середовище в залежності від кута постановки дисків до напрямку руху а (кут атаки) та кута нахилу у вертикальній площині $\beta$. Це зумовлює важливість вивчення механіки взаємодії дискових робочих органів з ґрунтом і дозволяє віднести такі напрями досліджень до актуальних науково-технічних задач, що сприяють створенню нових ефрективних засобів механізації обробітку ґрунту.

Аналіз публікацій і досліджень. Аналіз відомих досліджень в напрямку підвищення ефек- тивності дискових робочих органів ґрунтообробних знарядь вказує на різні методичні підходи у вирішенні поставлених наукових задач та їх реалізацію в теоретичному аспекті та практичних рекомендацій щодо застосування [5 - 11].

Досліджуючи взаємодію сферичних дискових робочих органів із ґрунтом І.А.Шевченко в [5] встановив вплив на показники якості і енергоємності роботи дискових ґрунтообробних знарядь кута атаки, діаметр і радіус сфери диска та його питомого навантаження при виконанні процесу.

Розглядаючи вплив геометричних параметрів диска на розподіл сил щодо визначених параметрів оптимізації, автором розглянуто рух ґрунту по поверхні робочого органу у вигляді матеріальної точки, що рухається по увігнутій поверхні з радіусом сфери $R$, яка рівномірно обертається навколо однієї з осей. Автором одержано рівняння руху матеріальної частинки по увігнутій сферичній поверхні дискового робочого органу. За результатами виконаних досліджень, в роботі установлено закономірності впливу конструктивно-технологічних параметрів на агротехнічні та енергетичні показники технологічного процесу дискування. 
В роботі [6] розглянуто задачу нарисної геометрії визначення висоти гребенів над дном борозни при обробці ґрунту лущильником. В наукових працях В.П.Ковбаси $[7,8]$ представлені фрізичні рівняння зв'язку напружень зі швидкостями десрормацій для ґрунтового середовища при дії на нього дискового робочого органу. Авторами [7] встановлено також, що надмірне збільшення кута атаки дисків може призводити до їх забивання ґрунтом і пожнивними залишками, тому значення граничного кута атаки на лущильниках не повинен перевищувати $35^{\circ}$. Доведено, що на якість обробітку ґрунту та енергоємність процесу обробітку для рівних значень механічних властивостей ґрунту найбільш суттєвий вплив мають діаметр диска Д, радіус його кривизни $R$, кут атаки $\alpha$ і кут нахилу ү. При цьому однаковий ефрект може бути досягнутий як зміною радіуса кривизни диска, так і кутом нахилу осі обертання $\mathrm{\gamma}$, що дає можливість вибирати раціональні параметри, виходячи з конкретних умов використання машин із дисковими робочими органами.

Виконаний аналіз відомих досліджень вказуе на те, кожна з представлених моделей взаємодії дискових робочих органів з ґрунтовим середовищем використовується дещо однобічно, окремо одна від одної без їх теоретичного узагальнення, що перешкоджає формуванню узагальнених підходів до вирішення означеної науково-технічної задачі.

Мета досліджень. Теоретично дослідити процес взаємодії ґрунтового середовища з дисковим робочим органом ґрунтообробного знаряддя і визначити складові сили опору.

Для досягнення поставленої мети дослідження запропоновано виконати наступні задачі.

1. Дослідити рух частинки ґрунту по увігнутій сфреричній поверхні робочого органу дискатора та визначити лінію контакту ґрунтового середовища із нею.

2. Визначити площу контакту ґрунтового середовища із поверхнею робочого органу дискатора.

3. Враховуючи напруження, що виникають в ґрунтовому середовищі при дії на нього дискового робочого органу визначити складові відповідної сили опору.

Нехай $P$ - частинка ґрунту масою $\mathrm{mp}$, що здійснює рух по поверхні дискового робочого органу, який представляється двовимірною сфрерою радіусом $R$ з центром в точці О, що обмежена колом діаметром $d$ з центром в точці $\mathrm{O}^{`}$ (рис. 1). Дисковий робочий орган виконує поступальний рух вздовж вісі $O{ }^{\prime} X$ зі швидкістю $V$ і обертовий вздовж вісі $O ` O$ з кутовою швидкістю $\omega$. Площина дискового робочого органу знаходиться під кутом до напряму його руху $O ` X$ (кут атаки $\alpha$ ) і під кутом до вертикальної осі $O ` Z$ (кут нахилу $\gamma$ ). Кут між віссю $O^{\circ} O$ складає з віссю $O z$ кут $\left(90^{\circ}-\gamma\right)$. Глибина обробітку ґрунту складає $h$, яка визначається від нижньої точки $D$ дискового робочого органу до горизонтальної поверхні ґрунту $A C X$.

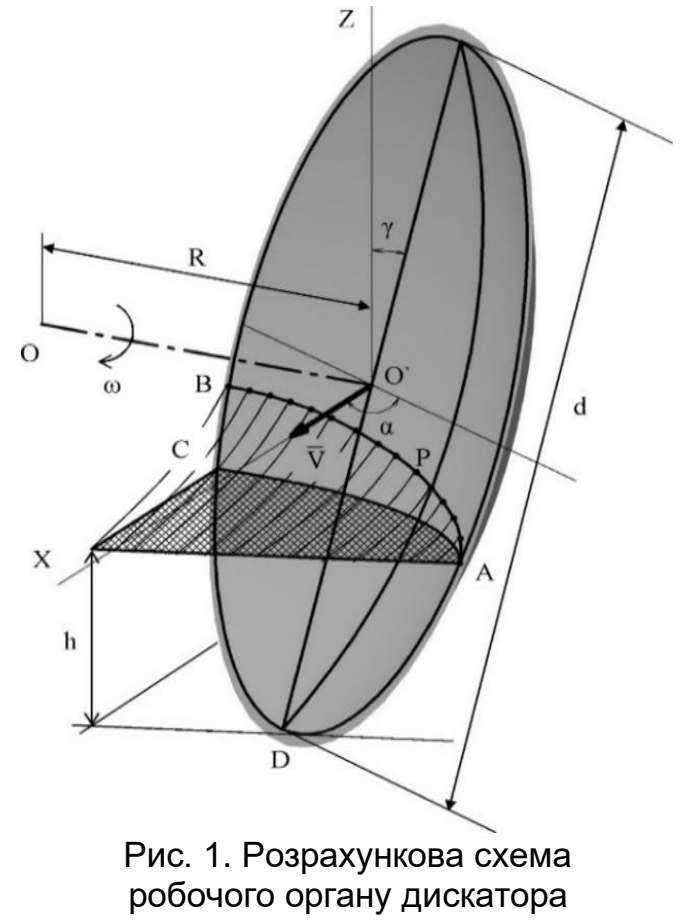

Під час взаємодії поверхні робочого органу дискатора із ґрунтовим середовищем виникає лінія їх контакту АВ (рис. 1), на якій спостерігається положення рівноваги частинок ґрунту. Лінія АС характеризує горизонтальну площину перетину поверхні робочого органу дискатора із горизонтальною поверхнею ґрунтового середовища. Зміщення ґрунту від лінії АС до лінії АВ відбувається під дією сили підпору шару ґрунту, що напливає на дисковий робочий орган, і відцентровою силою та силою Коріоліса, що виникають в результаті його обертання. При цьому контакт ґрунтового середовища із поверхнею робочого органу дискатора відбувається за криволінійною поверхнею АВCD.

Радіус $R$ сфрери можна визначити за фрормулою [6]:

$$
R=\frac{d}{2 \sin \zeta^{\prime}}
$$

де $\zeta$ - половина кута при вершині сектора дискового робочого органу, ${ }^{\circ}$ :

Модуль вектора кутової швидкості частинки, що знаходиться на диску, згідно досліджень [7] визначається залежністю

$$
\omega=\frac{2 V}{\mu d \cos \alpha \cos \gamma} .
$$

де $\mu$ - коефріцієнт ковзання диску при його обертанні. 
Розглянемо процес переміщення частинка ґрунту $P$ масою $m_{p}$ по поверхні робочого органу дискатора. Для цього введемо абсолютну систему координат $O x y z$, в якій площина $O x y €$ горизонтальною, а третя вісь $O z$ спрямована вертикально вгору (рис. 2).

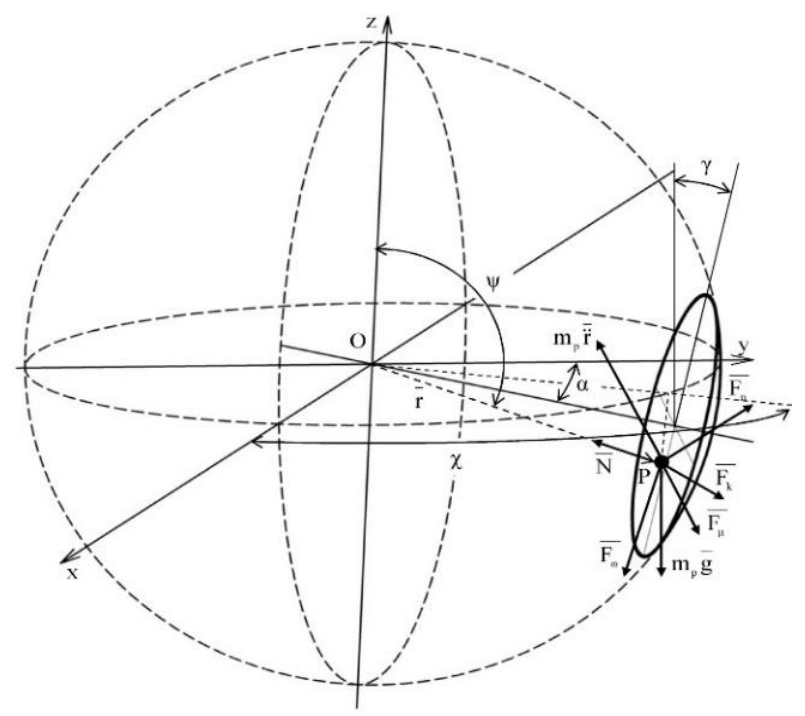

Рис. 2 Схема сил, що діють на частинку ґрунту в точці $P$ на сфрері, що задається сферичними координатами $(\psi, \chi)$

Відстань від початку координат до частинки ґрунту будемо задавати радіус-вектором $\bar{r}$. На частинка ґрунту масою $m_{p}$ діють:

- сила інерції $m_{p} \overline{\ddot{r}}$;

- сила тяжіння $m_{p} \bar{g}$;

- сила Коріоліса $\overline{F_{k}}=-2 m_{p}[\bar{\omega}, \overline{\dot{r}}]$;

- сила реакції поверхні диску $\bar{N}$;

- сила тертя ковзання $\overline{F_{\mu}}=\mu|\bar{N}| \frac{\bar{r}}{|\bar{r}|} ;$

- відцентрова сила $\overline{F_{\omega}}=m_{p} \omega^{2} \cdot \bar{r}$;

- сила підпору шару ґрунту [12]

$$
\overline{F_{n}}=m_{p} \frac{q}{\rho}\left(1-\frac{\overline{\dot{r}}}{V}\right),
$$

де $q$ - коефріцієнт об'ємного стиску ґрунту, м $^{-3}$; $\rho$ - об'ємна вага ґрунту, кг/м³.

Будемо встановлювати положення точки на сфрері за допомогою сфреричних кутів $\psi$ і $\chi$ : $\psi_{\min } \leq \psi \leq \psi_{\max }, \chi_{\min } \leq \chi \leq \chi_{\max }$ (рис. 2), де

$$
\begin{aligned}
& \psi_{\text {min }}=\frac{\pi}{2}+\gamma-\zeta=\frac{\pi}{2}+\gamma-\arcsin \frac{d}{2 R^{\prime}}, \\
& \psi_{\max }=\frac{\pi}{2}+\gamma+\zeta=\frac{\pi}{2}+\gamma+\arcsin \frac{d}{2 R},
\end{aligned}
$$

$$
\begin{aligned}
& \chi_{\text {min }}=\frac{\pi}{2}+\alpha-\zeta=\frac{\pi}{2}+\alpha-\arcsin \frac{d}{2 R^{\prime}} \\
& \chi_{\text {max }}=\frac{\pi}{2}+\alpha+\zeta=\frac{\pi}{2}+\alpha+\arcsin \frac{d}{2 R} .
\end{aligned}
$$

Абсолютна швидкість $\bar{v}=\overline{\dot{r}}$ частинки ґрунту $P$ у сфреричних координатах записується як

$$
\bar{v}=v_{\psi} \overline{e_{\psi}}+v_{\chi} \overline{e_{\chi}}
$$

де $v_{\psi}=R \dot{\psi}, v_{\chi}=R \sin \psi \dot{\chi}$ - проекції швидкості частинки ґрунту $\mathrm{P}$ у сферичних координатах, м/с; $\overline{e_{\psi}}, \overline{e_{\chi}}-$ одиничні вектори сфреричних координат.

Швидкість частинки ґрунту $P$ відносно диска, що обертається, набуває вигляду

$$
\overline{v^{\prime}}=v_{\psi}^{\prime} \overline{e_{\psi}}+v_{\chi}^{\prime} \overline{e_{\chi}}
$$

де

$$
\begin{gathered}
v_{\psi}^{\prime}=R \dot{\psi}+R \omega \sin (\pi / 2-\gamma) \sin \chi= \\
=R \dot{\psi}+R \omega \cos \gamma \sin \chi, \\
v_{\chi}^{\prime}=R \sin \psi \dot{\chi}+R \omega \sin (\pi / 2-\gamma) \times \\
\times \cos \psi \cos \chi-R \omega \cos (\pi / 2-\gamma) \sin \psi= \\
=R \sin \psi \dot{\chi}+R \omega \cos \gamma \cos \psi \cos \chi- \\
-R \omega \sin \gamma \sin \psi .
\end{gathered}
$$

У координатах $(\psi, \chi)$ рівняння ковзання частинки ґрунту $P$ по сфері залишимо у вигляді:

$$
\begin{gathered}
m_{p} R\left(-\sin ^{2} \psi \ddot{\chi}-\dot{\psi}^{2}\right)=-m_{p} g \cos \psi+N, \\
m_{p} R\left(\ddot{\psi}-\sin \psi \cos \psi \dot{\chi}^{2}\right)=m_{p} g \sin \psi+ \\
+m_{p} \frac{q}{\rho}\left(1-\frac{R \dot{\psi}+R \omega \cos \gamma \sin \chi}{V}\right)- \\
-\mu N(R \dot{\psi}+R \omega \cos \gamma \sin \chi) \div \\
\div\left[\begin{array}{c}
(R \dot{\psi}+R \omega \cos \gamma \sin \chi)^{2}+ \\
+\left(\begin{array}{c}
R \sin \psi \dot{\chi}-R \omega \sin \gamma \sin \psi+ \\
+R \omega \cos \gamma \cos \psi \sin \chi
\end{array}\right)^{2}
\end{array}\right]^{\frac{1}{2}}, \\
=m_{p} \frac{q}{\rho}\left(\begin{array}{c}
1-\frac{R \sin \psi \dot{\chi}}{V}+\frac{R \omega \sin \gamma \sin \psi}{V}- \\
\left.-\frac{R \omega \cos \gamma \cos \psi \sin \chi}{V}\right)- \\
-\mu N\left(\begin{array}{c}
R \sin \psi \dot{\chi}-R \omega \sin \gamma \sin \psi+ \\
+R \omega \cos \gamma \cos \psi \sin \chi
\end{array}\right) \div \\
\quad\left[\begin{array}{c}
R \dot{\psi}+R \omega \cos \gamma \sin \chi)^{2}+ \\
R \sin \psi \dot{\chi}-R \omega \sin \gamma \sin \psi+ \\
+R \omega \cos \gamma \cos \psi \sin \chi
\end{array}\right)^{2}
\end{array}\right]^{\frac{1}{2}} .
\end{gathered}
$$

Перше рівняння системи (9), що виражає проекцію рівнянь Ньютона на нормаль до поверхні сфери, дозволить знайти нормальну реакцію $N$. 
Друге і третє рівняння системи (9) задають рух в проекції на осі з одиничними векторами $\overline{e_{\psi}}, \overline{e_{\chi}}$.

Для визначення положення рівноваги частинки ґрунту щодо абсолютного простору покладемо для цього $\dot{\psi}=0$ і $\dot{\chi}=0$ :

$$
\begin{gathered}
0=-m_{p} g \cos \psi+N \\
0=m_{p} g \sin \psi+ \\
+m_{p} \frac{q}{\rho}\left(1-\frac{R \omega \cos \gamma \sin \chi}{V}\right)- \\
-\mu N R \omega \cos \gamma \sin \chi \times \\
\times\left[\begin{array}{c}
(R \omega \cos \gamma \sin \chi)^{2}+ \\
+\left(\begin{array}{c}
R \omega \cos \gamma \cos \psi \sin \chi- \\
-R \omega \sin \gamma \sin \psi
\end{array}\right)^{2}
\end{array}\right]^{-\frac{1}{2}} \\
0=m_{p} \frac{q}{\rho}\left(\begin{array}{c}
1+\frac{R \omega \sin \gamma \sin \psi}{V}- \\
-\frac{R \omega \cos \gamma \cos \psi \sin \chi}{V}
\end{array}\right)^{-} \\
-\mu N\left(\begin{array}{c}
R \omega \cos \gamma \cos \psi \sin \chi- \\
-R \omega \sin \gamma \sin \psi
\end{array}\right) \times \\
\times\left[\begin{array}{c}
(R \omega \cos \gamma \sin \chi)^{2}+ \\
+\left(\begin{array}{c}
R \omega \cos \gamma \cos \psi \sin \chi- \\
-R \omega \sin \gamma \sin \psi
\end{array}\right)^{2}
\end{array}\right]^{-\frac{1}{2}}
\end{gathered}
$$

Виражаючи 3 першого рівняння системи $N$ і підставляючи в друге і третє отримуємо

$$
\begin{gathered}
N=m_{p} g \cos \psi, \\
0=m_{p} g \sin \psi+ \\
+m_{p} \frac{q}{\rho}\left(1-\frac{R \omega \cos \gamma \sin \chi}{V}\right)- \\
-\mu m_{p} g \cos \psi R \omega \cos \gamma \sin \chi \times \\
\times\left[\begin{array}{c}
(R \omega \cos \gamma \sin \chi)^{2}+ \\
+\left(\begin{array}{c}
R \omega \cos \gamma \cos \psi \sin \chi- \\
-R \omega \sin \gamma \sin \psi
\end{array}\right)^{2}
\end{array}\right]^{-\frac{1}{2}} \\
0=m_{p} \frac{q}{\rho}\left(\begin{array}{c}
1+\frac{R \omega \sin \gamma \sin \psi}{V}- \\
-\frac{R \omega \cos \gamma \cos \psi \sin \chi}{V}
\end{array}\right)- \\
-\mu m_{p} g \cos \psi\left(\begin{array}{c}
R \omega \cos \gamma \cos \psi \sin \chi- \\
-R \omega \sin \gamma \sin \psi
\end{array}\right) \times \\
\times\left[\begin{array}{c}
(R \omega \cos \gamma \sin \chi)^{2}+ \\
+\left(\begin{array}{c}
R \omega \cos \gamma \cos \psi \sin \chi- \\
-R \omega \sin \gamma \sin \psi
\end{array}\right)^{2}
\end{array}\right]^{-\frac{1}{2}}
\end{gathered}
$$
маємо

Перетворивши рівняння (11) і підставивши (2)

$$
\begin{gathered}
\sin \psi+\frac{q}{\rho g}\left(1-\frac{\sin \chi}{\mu \cos \alpha \sin \zeta}\right)= \\
=\mu \cos \psi \cos \gamma \sin \chi \times \\
\times\left[(\cos \gamma \sin \chi)^{2}+\left(\begin{array}{c}
\cos \gamma \cos \psi \sin \chi- \\
-\sin \gamma \sin \psi
\end{array}\right)^{2}\right]^{-\frac{1}{2}},
\end{gathered}
$$

$$
\begin{aligned}
& \frac{q}{\rho g}\left(1-\frac{\cos \gamma \cos \psi \sin \chi-\sin \gamma \sin \psi}{\mu \cos \alpha \cos \gamma \sin \zeta}\right)= \\
= & {[\mu \cos \psi(\cos \gamma \cos \psi \sin \chi-\sin \gamma \sin \psi)] \times } \\
\times & {\left[(\cos \gamma \sin \chi)^{2}+\left(\begin{array}{c}
\cos \gamma \cos \psi \sin \chi- \\
-\sin \gamma \sin \psi
\end{array}\right)^{2}\right]^{-\frac{1}{2}} . }
\end{aligned}
$$

Систему рівнянь (11) відносно $\psi$ і $\chi$ будемо вирішувати в програмному пакеті Mathematica. Приймаючи $g=9,8 \mathrm{~m} / \mathrm{c}^{2}, q=1,3 \cdot 10^{-3} \mathrm{H} / \mathrm{m}^{3}$ [5]; $\rho=1340$ кг $/ \mathrm{m}^{3} ; \alpha=15^{\circ} ; \gamma=10^{\circ} ; \quad d=0,4 \mathrm{M}$; $R=0,66$ м; $h=0,1$ м отримуємо графрічну інтерпретацію дискового робочого органу і лінії контакту $з$ ґрунтовим середовищем (рис. 3).

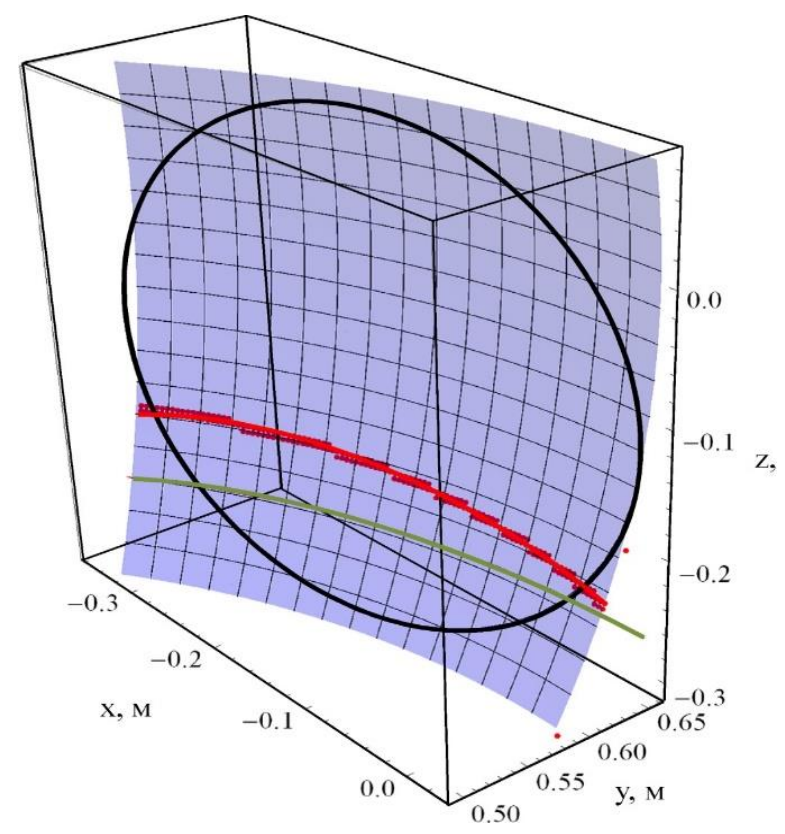

Рис. 3 Графічна інтерпретацію дискового робочого органу і лінії контакту з грантовим середовищем

При цьому рівняння лінії контакту можна представити, як в параметричному так і в звичайному вигляді:

$$
\left\{\begin{array}{c}
\mathrm{x}(t)=-0,320752+0,000978761 \mathrm{t}+ \\
+8,63534 \cdot 10^{-6} \mathrm{t}^{2}-2,2426 \cdot 10^{-8} \mathrm{t}^{3} \\
\mathrm{y}(t)=0,542725+0,000708602 \mathrm{t}+ \\
+1,12761 \cdot 10^{-6} \mathrm{t}^{2}-1,46553 \cdot 10^{-8} \mathrm{t}^{3} \\
\mathrm{z}(t)=-0,179942-0,00023068 \mathrm{t}+ \\
+2,1464 \cdot 10^{-6} \mathrm{t}^{2}-1,19451 \cdot 10^{-8} \mathrm{t}^{3} \\
\mathrm{z}(\mathrm{x}, \mathrm{y})=0,719908+1,45223 \mathrm{x}+ \\
+2,57464 \mathrm{x}^{2}-5,72681 \mathrm{y}- \\
\quad-2,29588 \mathrm{xy}+6,77665 \mathrm{y}^{2} .
\end{array}\right.
$$

Статистична обробка рівняння (13) приведена в таблиці 1. 
Таблиця 1. Статистична обробка рівняння (13)

\begin{tabular}{|c|c|c|c|c|}
\hline 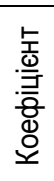 & 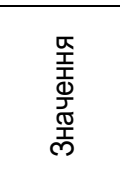 & 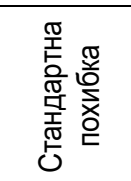 & 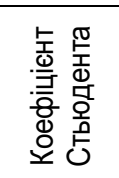 & Р-значення \\
\hline$a_{00}$ & 0,71991 & 0,120543 & 5,97222 & $1,14766 \cdot 10^{-8}$ \\
\hline$a_{10}$ & 1,45223 & 0,094488 & 15,3694 & $4,64448 \cdot 10^{-35}$ \\
\hline$a_{20}$ & $-5,72681$ & 0,403213 & $-14,203$ & $1,39588 \cdot 10^{-31}$ \\
\hline$a_{12}$ & $-2,29588$ & 0,147059 & $-15,612$ & $8,85312 \cdot 10^{-36}$ \\
\hline$a_{11}$ & 2,57464 & 0,040729 & 63,2139 & $1,30433 \cdot 10^{-128}$ \\
\hline$a_{22}$ & 6,77665 & 0,336936 & 20,1125 & $9,6213 \cdot 10^{-49}$ \\
\hline
\end{tabular}

Для знаходження площі контакту ґрунтового середовища і робочого органу дискатора скористаємося формулою [13]:

$$
S=\iint_{A B C D} \sqrt{1+\left(\frac{\partial z}{\partial x}\right)^{2}+\left(\frac{\partial z}{\partial y}\right)^{2}} d x d y
$$

де ABCD - фрігура що обмежена лініями: рівнянням (13) і колом діаметром $d$ із центром в точці:

$$
\begin{gathered}
x_{c}=R \sin \left(\frac{\psi_{\max }+\psi_{\min }}{2}\right) \cos \left(\frac{\chi_{\max }+\chi_{\min }}{2}\right), \\
y_{c}=R \sin \left(\frac{\psi_{\max }+\psi_{\min }}{2}\right) \sin \left(\frac{\chi_{\max }+\chi_{\min }}{2}\right), \\
z_{c}=R \cos \left(\frac{\psi_{\max }+\psi_{\min }}{2}\right) .
\end{gathered}
$$

Тоді рівняння нижньої частини зазначеного кола має вигляд:

$$
\begin{gathered}
z=R \cos \left(\frac{\psi_{\max }+\psi_{\min }}{2}\right)- \\
-\left[\begin{array}{c}
\left.\frac{d^{2}}{4}-\left(\begin{array}{c}
x-R \sin \left(\frac{\psi_{\max }+\psi_{\min }}{2}\right) \times \\
\times \cos \left(\frac{\chi_{\max }+\chi_{\min }}{2}\right)
\end{array}\right)^{2}+\right]^{\frac{1}{2}} \\
+\left(\begin{array}{c}
x-R \sin \left(\frac{\psi_{\max }+\psi_{\min }}{2}\right) \times \\
\times \sin \left(\frac{\chi_{\max }+\chi_{\min }}{2}\right)
\end{array}\right)^{2}
\end{array}\right]^{2} .
\end{gathered}
$$

3 використанням розробленої програми в програмному пакеті Mathematica було проведено варіювання глибини обробітку ґрунту $h$ від 0,03 м до $0,12 \mathrm{M}$, кута атаки $\alpha$ і кута нахилу ү робочого органу дискатора в діапазоні від $0^{\circ}$ (0 рад) до $30^{\circ}(\pi / 6$ рад) і визначені значення площі контакту $S$. Апроксимуючі отримані дані отримано рівняння регресії другого порядку для двох фракторів (рис. 4):

\begin{tabular}{|c|c|c|c|c|}
\hline 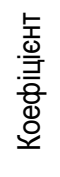 & Значення & 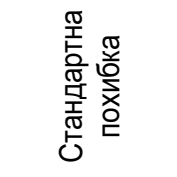 & 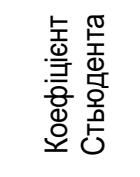 & Р-значення \\
\hline$a_{00}$ & $-0,00185791$ & 0,000166343 & $-11,1691$ & $1,10204 \cdot 10^{-18}$ \\
\hline$a_{10}$ & 0,224608 & 0,00268961 & 83,5094 & $4,57602 \cdot 10^{-87}$ \\
\hline$a_{20}$ & 0,00433771 & 0,000684907 & 6,33328 & $9,24664 \cdot 10^{-9}$ \\
\hline$a_{30}$ & 0,00143915 & 0,000684907 & 2,10124 & 0,0384153 \\
\hline$a_{12}$ & 0,108132 & 0,00339325 & 31,8668 & $8,3658 \cdot 10^{-51}$ \\
\hline$a_{13}$ & 0,0182 & 0,00339325 & 5,36361 & $6,26894 \cdot 10^{-7}$ \\
\hline$a_{23}$ & 0,00197823 & 0,000922209 & 2,1451 & 0,0346382 \\
\hline$a_{11}$ & 0,572986 & 0,0156067 & 36,7141 & $6,02784 \cdot 10^{-56}$ \\
\hline$a_{22}$ & 0,0111632 & 0,00110225 & 10,1276 & $1,55186 \cdot 10^{-16}$ \\
\hline & $-0,000297924$ & 0,00110225 & $-0,270287$ & 0,787558 \\
\hline
\end{tabular}

$$
\begin{gathered}
S(h, \alpha, \gamma)=-0,00185791+0,224608 \mathrm{~h}+ \\
+0,572986 \mathrm{~h}^{2}+0,00433771 \beta+ \\
+0,108132 \mathrm{~h} \alpha+0,0111632 \alpha^{2}+ \\
+0,00143915 \gamma+0,0182 \mathrm{~h} \gamma+ \\
+0,00197823 \alpha \gamma-0,000297924 \gamma^{2} .
\end{gathered}
$$

Статистична обробка рівняння (17) приведена в таблиці 2.

Таблиця 2. Статистична обробка рівняння (17)

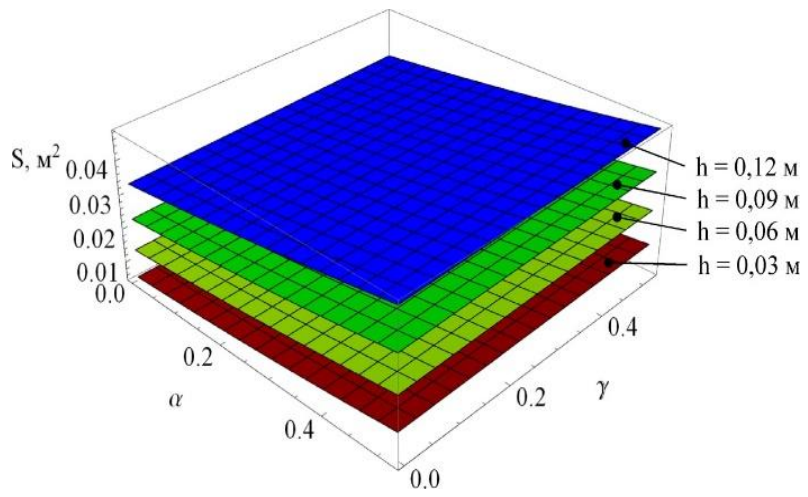

Рис. 4. Залежність площі контакту ґрунтового середовища і робочого органу дискатора від його кутів атаки $\alpha$ і нахилу $\gamma$ та глибини обробітку ґрунту $h$

Для визначення сили опору ґрунтового середовища при дії на нього дискового робочого органу використаємо результати досліджень [8], а саме аналітичні залежності компонентів нормальних напружень для пружно-в'язко-пластичного ґрунтового середовища:

$$
\begin{aligned}
& \sigma_{x}=\frac{2}{9} \mu\left(\begin{array}{c}
3 e^{\frac{2 K_{2}(1+v)}{3(-1+2 v)}}\left(2 \dot{\varepsilon}_{x}-\dot{\varepsilon}_{y}-\dot{\varepsilon}_{z}\right)- \\
-\frac{e^{K_{2}}(1+v)\left(\dot{\varepsilon}_{x}+\dot{\varepsilon}_{y}+\dot{\varepsilon}_{z}\right)}{-1+2 v}
\end{array}\right), \\
& \sigma_{y}=\frac{2}{9} \mu\left(\begin{array}{c}
3 e^{\frac{2 K_{2}(1+v)}{3(-1+2 v)}}\left(2 \dot{\varepsilon}_{y}-\dot{\varepsilon}_{x}-\dot{\varepsilon}_{z}\right)- \\
-\frac{e^{K_{2}}(1+v)\left(\dot{\varepsilon}_{x}+\dot{\varepsilon}_{y}+\dot{\varepsilon}_{z}\right)}{-1+2 v}
\end{array}\right), \\
& \sigma_{z}=\frac{2}{9} \mu\left(\begin{array}{c}
3 e^{\frac{2 K_{2}(1+v)}{3(-1+2 v)}}\left(2 \dot{\varepsilon}_{z}-\dot{\varepsilon}_{y}-\dot{\varepsilon}_{x}\right)- \\
-\frac{e^{K_{2}}(1+v)\left(\dot{\varepsilon}_{x}+\dot{\varepsilon}_{y}+\dot{\varepsilon}_{z}\right)}{-1+2 v}
\end{array}\right),
\end{aligned}
$$




$$
\begin{gathered}
K_{2}=-27 L(-1+2 v) \times \\
\times \frac{\tau_{0} \cos \kappa+\frac{2 e^{K_{1} \mu(1+v)\left(\dot{\varepsilon}_{x}+\dot{\varepsilon}_{y}+\dot{\varepsilon}_{z}\right) \sin \kappa}}{9-18 v}}{4 \sqrt{2} \mu(1+v) \sqrt{\frac{E(-1+v)}{\left(-1+v+2 v^{2}\right) \rho}}(-3+\sin \kappa)} \\
K_{1}=-\frac{E L}{\mu(1+v) \sqrt{\frac{E(-1+v)}{\left(-1+v+2 v^{2}\right) \rho}}},
\end{gathered}
$$

де $\sigma_{x}, \sigma_{y}, \sigma_{z}$ - компоненти напружень, Па; $\dot{\varepsilon}_{x}, \dot{\varepsilon}_{y}, \dot{\varepsilon}_{z}$ - компоненти швидкостей відносних деформацій, 1/c; $v$ - коефріцієнт Пуассона; $E$ - модуль пружності лінійних деформацій, Па; $\mu$ - коефріцієнт в'язкості зсувних деформацій, Па·с; к - коефіцієнт внутрішнього тертя ґрунту; то - напруження початкового зсуву ґрунту, Па; $L$ - відстань, на якій затухає хвиля напружень у ґрунті, м; $\rho$ - щільність

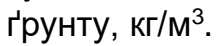

Проекцію сили опору на вісі Ox, Oy, Oz можна визначити за фоомулами:

$$
\begin{aligned}
& F_{x}=\iint_{A B C D} \sigma_{x} d y d z \\
& F_{y}=\iint_{A B C D} \sigma_{y} d x d z \\
& F_{z}=\iint_{A B C D} \sigma_{z} d x d y
\end{aligned}
$$

де $A B C D$ - фрігура що обмежена лініями: рівнянням (13) і (16)

Для переводу декартових координат у сферичні використовується наступні залежності [12]:

$$
\begin{gathered}
x=\mathrm{R} \sin \psi \cos \chi, \\
y=\mathrm{R} \sin \psi \sin \chi, \\
z=\mathrm{R} \cos \psi .
\end{gathered}
$$

Для похідних за часом і диференціалів отримуємо:

$$
\begin{gathered}
\dot{x}=R \dot{\psi} \cos \psi \cos \chi-R \dot{\chi} \sin \psi \sin \chi, \\
\dot{y}=R \dot{\psi} \cos \psi \sin \chi+\mathrm{R} \dot{\chi} \sin \psi \cos \chi, \\
\dot{z}=-R \dot{\psi} \sin \psi
\end{gathered}
$$

$d x=R \cos \psi \cos \chi d \psi-R \sin \psi \sin \chi d \chi$,

$d y=R \cos \psi \sin \chi d \psi+R \sin \psi \cos \chi d \chi$, $d z=-R \sin \psi d \psi$.

Враховуючи, що $\dot{\varepsilon}_{x}=\frac{\dot{x}}{L}, \dot{\varepsilon}_{y}=\frac{\dot{y}}{L}, \dot{\varepsilon}_{z}=\frac{\dot{z}}{L}$ отримуємо:

$$
\begin{aligned}
& 2 \dot{\varepsilon}_{x}-\dot{\varepsilon}_{y}-\dot{\varepsilon}_{z}=\frac{1}{L}\left(\begin{array}{c}
2 R \dot{\psi} \cos \psi \cos \chi- \\
-2 R \dot{\chi} \sin \psi \sin \chi-
\end{array}\right. \\
& \left.\begin{array}{l}
-R \dot{\psi} \cos \psi \sin \chi- \\
\dot{\alpha} \sin \psi \cos \chi+R \dot{\psi} \sin \psi
\end{array}\right) \\
& -\mathrm{R} \dot{\chi} \sin \psi \cos \chi+R \dot{\psi} \sin \psi), \\
& 2 \dot{\varepsilon}_{y}-\dot{\varepsilon}_{x}-\dot{\varepsilon}_{z}=\frac{1}{L}\left(\begin{array}{c}
2 \mathrm{R} \dot{\psi} \cos \psi \sin \chi+ \\
+2 \mathrm{R} \dot{\chi} \sin \psi \cos \chi-
\end{array}\right.
\end{aligned}
$$

$$
\begin{aligned}
& \left.\begin{array}{c}
-R \dot{\psi} \cos \psi \cos \chi+ \\
\dot{\chi} \sin \psi \sin \chi+R \dot{\psi} \sin \psi
\end{array}\right), \\
& 2 \dot{\varepsilon}_{z}-\dot{\varepsilon}_{y}-\dot{\varepsilon}_{x}=\frac{1}{L}\left(\begin{array}{c}
2 \mathrm{R} \dot{\psi} \sin \psi- \\
-R \dot{\psi} \cos \psi \cos \chi+ \\
+R \dot{\chi} \sin \psi \sin \chi-
\end{array}\right. \\
& \left.\begin{array}{c}
-R \dot{\psi} \cos \psi \sin \chi+ \\
+\mathrm{R} \dot{\chi} \sin \psi \cos \chi
\end{array}\right) \\
& \dot{\varepsilon}_{x}+\dot{\varepsilon}_{y}+\dot{\varepsilon}_{z}=\frac{1}{L}\left(\begin{array}{l}
R \dot{\psi} \cos \psi \cos \chi- \\
-R \dot{\chi} \sin \psi \sin \chi+
\end{array}\right. \\
& \left.\begin{array}{c}
+R \dot{\psi} \cos \psi \sin \chi+ \\
\dot{\chi} \sin \psi \cos \chi-R \dot{\psi} \sin \psi
\end{array}\right) .
\end{aligned}
$$

Підставляючи (28) і (29) в (23)-(25) отримуємо проекції сили опору на вісі $O x, O y, O z$. Однак представлені інтеграли важко вирішувати аналітичним способом. Тому скористаємося програмним пакетом Mathematica і визначимо залежності проекцій сили опору від кутів атаки $\alpha$ і нахилу у робочого органу дискатора в діапазоні від (0 рад) до $30^{\circ}(\pi / 6$ рад), швидкості його переміщення $V(1-4 \mathrm{~m} / \mathrm{c})$ та глибини обробітку ґрунту $h$ (0,03 - 0,12 м). Апроксимуючі отримані дані отримано рівняння регресії для трьох проекцій сили опору:

$$
\begin{gathered}
F_{x}=5627,99 V(-0,00324251+ \\
+h^{2}+0,0194825 \alpha^{2}+\alpha(0,00757036+ \\
+0,00345249 \gamma)+h(0,391995+ \\
+0,188717 \alpha+0,0317635 \gamma)+ \\
\left.+0,00251167 \gamma-0,00051995 \gamma^{2}\right)(\cos \alpha+ \\
+\sin \alpha(0,307692 \cos \gamma+0,307692 \sin \gamma)), \\
F_{y}=1731,69 V(-0,00324251+ \\
+h^{2}+0,0194825 \alpha^{2}+\alpha(0,00757036+ \\
+0,00345249 \gamma)+h(0,391995+ \\
+0,188717 \alpha+0,0317635 \gamma)+ \\
\left.+0,00251167 \gamma-0,00051995 \gamma^{2}\right) \times \\
\times(\cos \alpha+\sin \alpha(3,25 \cos \gamma+\sin \gamma)), \\
F_{z}=1731,69 V(-0,00324251+ \\
+h^{2}+0,0194825 \alpha^{2}+\alpha(0,00757036+ \\
+0,00345249 \gamma)+h(0,391995+ \\
+0,188717 \alpha+0,0317635 \gamma)+ \\
\left.+0,00251167 \gamma-0,00051995 \gamma^{2}\right)(\cos \alpha+ \\
+\sin \alpha(\cos \gamma+3,25 \sin \gamma)),
\end{gathered}
$$

Графрічна інтерпретація залежностей (30)(32) представлена на рис. 5 - 6.

\section{Висновки}

1. В результаті теоретичних досліджень переміщення частинки ґрунту по увігнутій сферичній поверхні робочого органу дискатора з урахуванням сили підпору шару ґрунту, що напливає на дисковий робочий орган, відцентровою сили та сили Коріоліса, що виникають в результаті його обертання, розроблено програмний код в 
програмному пакеті Mathematica, який дозволяє визначити площу та рівняння лінії контакту ґрунтового середовища із поверхнею робочого органу дискатора в залежності від його конструктивних параметрів (радіус сореричної поверхні $R$, діаметр диска $d$ ), кутів атаки $\alpha$ і нахилу $\gamma$ та глибини обробітку ґрунту $h$.

2. Враховуючи отримані залежності площі та рівняння лінії контакту ґрунтового середовища із поверхнею робочого органу дискатора та використовуючи відомі аналітичні закономірності для компонентів нормальних напружень пружнов'язко-пластичного ґрунтового середовища, розроблено програмний код в програмному пакеті Mathematica, який дозволяє визначати залежності проекцій сили опору від кутів атаки $\alpha$ і нахилу у робочого органу дискатора, швидкості його переміщення $V$ та глибини обробітку ґрунту $h$.

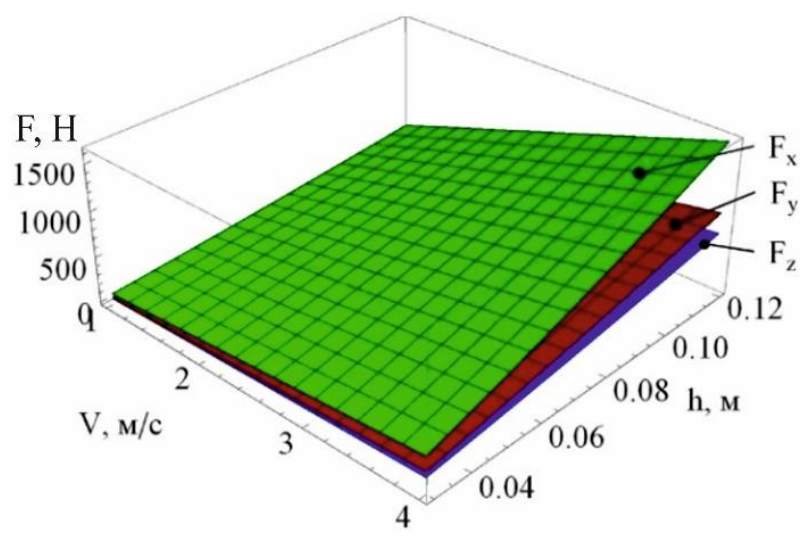

Рис. 5 Залежності проекцій сили опору від швидкості переміщення робочого органу дискатора $V$ та глибини обробітку ґрунту $h$ при $\alpha=15^{\circ}, \gamma=10^{\circ}$

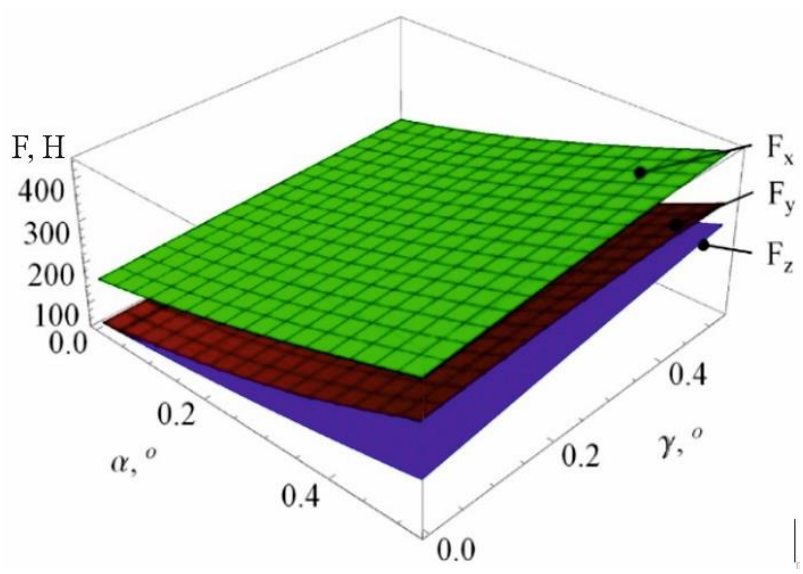

Рис. 6 Залежності проекцій сили опору від кутів атаки $\alpha$ і нахилу $\gamma$ робочого органу дискатора при $V=3$ м/с, $h=0,03$ м

\section{Література:}

1. Гуков, Я.С. Обробіток ґрунту. Технологія і техніка. Механіко-технологічне обґрунтування енергозберігаючих засобів для механізації обробітку ґрунту в умовах України [Текст]: наукове видання. Київ: ДІА, 2007. 276 с.

2. Заїка, П.М. Теорія сільськогосподарських машин. Т. 1 (4.1). Машини та знаряддя для обробітку ґрунту: монографія. Харків: ОКО, 2001. 444 с.

3. Сучасні тенденції розвитку конструкцій сільськогосподарської техніки : навч. посіб. / Кравчук В.І. та ін. - Київ: Аграрна наука, 2004. 396 с.

4. Mogilnay O., Paschenko V., Kharchenko S., Domachenko V., Siedykh K. Mathematical modeling of operational stability of sowing machines' mechanical systems. Eastern-European Journal of Enterprise technologies. 2018. № 4/1 (94): 37-47.

5. Шевченко, І.А. Керування агрофізичним станом ґрунтового середовища: монографрія. Київ: Видавничий дім «Вініченко», 2016. 320 с.

6. Бакум М.В., Ящук Д.А. Проектування ґрунтообробних машин з дисковими робочими органами: навчальний посібник. Харків: ХНТУСГ, 2011. 34 c.

7. Гуцол О.П., Ковбаса В.П. Обґрунтування параметрів і режимів руху ґрунтообробних машин з дисковими робочими органами: монографрія. Київ, 2016. 145 с.

8. Моделювання процесу взаємодії робочих органів сільськогосподарських машин з ґрунтом / В.П. Ковбаса та ін. Науковий вісник НАУ. 1997. Вип.2. С. 117-123.

9. Кушнарев С.А., Погорелый В.В., Чуб С.А. Кинематика точек сферических дисков почвообрабатывающих орудий при взаимодействии с почвой. Вісник Харківського національного технічного університету сільського господарства ім. Петра Василенка. 2008. Вип.75, Т.1. С.121-127.

10. Кушнарев, А.С. Дискатор - новое почвообрабатывающее орудие, обеспечивающее переход от традиционной технологии производства сельскохозяйственной продукции к энергосберегающей технологии No-till: монография. Белая Церковь, 2010. 60 с.

11. Сохт К.А., Трубилин Е.И., Коновалов В.И. Дисковые бороны и лущильники. Проектирование технологических параметров: учеб. пособие. Краснодар: КубГАУ, 2014. 164 с.

12. Горячкин, В.П. Теория разрушения почв: собр. соч. Москва: Колос, 1968. 382 с.

13. Корн Г., Корн Т. Справочник по математике для научных работников и инженеров. Москва: Наука, 1974. 832 с. 


\section{References:}

1. Ghukov, Ja. S. (2007) Obrobitok gruntu. Tekhnologhija i tekhnika. Mekhaniko-tekhnologhichne obgruntuvannja energhozberighajuchykh zasobiv dlja mekhanizaciji obrobitku gruntu $v$ umovakh Ukrajiny: naukove vydannja. Kyjiv: DIA. $276 \mathrm{p}$.

2. Zajika, P.M. (2001) Teorija siljsjkoghospodarsjkykh mashyn. T. 1(4.1). Mashyny ta znarjaddja dlja obrobitku gruntu: monoghrafija. Kharkiv: OKO. 444 p.

3. Kravchuk, V.I. et al. (2004) Suchasni tendenciji rozvytku konstrukcij siljsjkoghospodarsjkoji tekhniky : navch. posib. Kyjiv: Aghrarna nauka. 396 p.

4. Mogilnay, O. et al. (2018) 'Mathematical modeling of operational stability of sowing machines' mechanical systems', Eastern-European Journal of Enterprise technologies, (4/1 (94)), pp. 37-47.

5. Shevchenko, I.A. (2016) Keruvannja aghrofizychnym stanom gruntovogho seredovyshha: monoghrafija. Kyjiv: Vydavnychyj dim «Vinichenko». 320 p.

6. Bakum, M.V., Jashhuk, D.A. (2011) Proektuvannja gruntoobrobnykh mashyn z dyskovymy robochymy orghanamy: navchaljnyj posibnyk. Kharkiv: KhNTUSGh. 34 p.

7. Ghucol, O.P., Kovbasa, V.P. (2016) Obgruntuvannja parametriv i rezhymiv rukhu gruntoobrobnykh mashyn $z$ dyskovymy robochymy orghanamy: monoghrafija. Kyjiv. 145 p.

8. Kovbasa, V.P. et al. (1997) 'Modeljuvannja procesu vzajemodiji robochykh orghaniv siljsjkoghospodarsjkykh mashyn z gruntom', Naukovyj visnyk NAU, 2, pp. 117-123.

9. Kushnarev, S.A., Poghorelyj, V.V., Chub, S.A. (2008) 'Kynematyka tochek sferycheskykh dyskov pochvoobrabatyvajushhykh orudyj pry vzaymodejstvyy s pochvoj' Visnyk Kharkivsjkogho nacionaljnogho tekhnichnogho universytetu siljsjkogho ghospodarstva im. Petra Vasylenka, (75(1)), pp.121-127.

10. Kushnarev, A.S. (2010) Dyskator - novoe pochvoobrabatblvajushhee orudye, obespechyvajushhee perekhod ot tradycyonnoj tekhnologhyy proyzvodstva seljskokhozjajstvennoj produkcyy $k$ эnerghosbereghajushhej tekhnologhyy No-till: monoghrafyja. Belaja Cerkovj. 60 p.

11. Sokht, K.A., Trubilin, Ye.I., Konovalov, V.I. (2014) Diskovye borony i lushchilniki. Proektirovanie tekhnologicheskikh parametrov: ucheb. posobie. Krasnodar: KubGAU. 164 p.

12. Goryachkin, V.P. (1968) Teoriya razrusheniya pochv: sobr. soch. Moskva: Kolos. 382 p.

13. Korn,G., Korn, T. (1974) Spravochnik po matematike dlya nauchnykh rabotnikov $i$ inzhenerov. Moskva: Nauka. 832 p.

\section{Аннотация}

\section{Физико-математическая модель взаимодействия диска с почвой}

\section{А.В. Козаченко, К.В. Седых, О.М.Волковский}

Представлены результаты теоретических исследований взаимодействия почвенной среды с дисковым рабочим органом почвообрабатывающего орудия и определены составляющие силы сопротивления путем исследования движения частицы почвы по вогнутой сферической поверхности рабочего органа дискатора и определения линии контакта почвенной среды с ними; определения площади контакта почвенной среды с поверхностью рабочего органа дискатора; учитывая напряжения, возникающие в почвенном среде при воздействии на него дискового рабочего органа определены составляющие соответствующей силы сопротивления.

В результате аналитических исследований перемещения частицы почвы по вогнутой сферической поверхности рабочего органа дискатора с учетом силы подпора слоя почвы, наплывающего на дисковый рабочий орган, центробежной силы и силы Кориолиса, возникающих в результате его вращения, разработан программный код в программном пакете Mathematica, который позволяет определять площадь и уравнение линии контакта почвенной среды с поверхностью рабочего органа дискатора в зависимости от его конструктивных параметров: радиуса сфрерической поверхности $R$ и диаметра диска $d$, угла атаки $\alpha$ и угла наклона $\gamma$ и глубины обработки почвы $h$.

Учитывая полученные зависимости площади и уравнение линии контакта почвенной среды с поверхностью рабочего органа дискатора и используя известные аналитические закономерности для компонентов нормальных напряжений упруго-вязко-пластической почвенной среды, разработан программный код в программном пакете Mathematica, который позволяет определять зависимости проекций силы сопротивления от углов атаки $\alpha$ и наклона ү рабочего органа дискатора, скорости его перемещения $V$ и глубины обработки почвы $h$. Сделаны соответствующие выводы относительно полученных результатов теоретических исследований.

Ключевые слова: дискатор, дисковые рабочие органы, угол атаки, угол наклона, качество обработки, параметры сферического диска, энергоемкость. 


\begin{abstract}

\section{Physico-mathematical model of disk interaction with soil}

\section{O.V. Kozachenko, K.V. Siedykh, O.M. Volkoskiy}

The results of theoretical researches of interaction of a spherical disk with soil are presented. As a result of analytical studies of the movement of soil particles on the concave spherical surface of the working body of the disc, taking into account the force of support of the soil layer flowing to the disk working body, centrifugal force and Coriolis force resulting from its rotation, developed software code in Mathematica allows to determine the area and equation of the line of contact of the soil environment with the surface of the working body of the disc depending on its design parameters: the radius of the spherical surface $R$ and the diameter of the disc $d$, the angle of attack $\alpha$ and the angle of inclination $y$ and tillage depth $h$.

Taking into account the obtained dependences of the area and equation of the line of contact of the soil environment with the surface of the working body of the disc and using known analytical laws for the components of normal stresses of elastic-viscous-plastic soil environment, developed software code in Mathematica software angles of attack $\alpha$ and inclination $\gamma$ of the working body of the disc, the speed of its movement $V$ and the depth of tillage $h$. The corresponding conclusions concerning the received results of theoretical researches are made.
\end{abstract}

Keywords: disc harrow, disk working bodies, angle of attack, angle of inclination, quality of tillage, parameters of spherical disk, energy consumption.

\title{
Бібліографічне посилання/ Bibliography citation: Harvard
}

Kozachenko, O. V., Siedykh, K. V. and Volkoskiy, O. M. (2020) 'Physico-mathematical model of disk interaction with soil', Engineering of nature management, (2(16), pp. $69-77$.

Подано до редакції / Received: 06.08.2020 